\title{
Exploring the Utility of Word of Mouth Advertisement in Improving Product Sales: The Case of Selected Companies in the Kumasi Metropolis of Ghana
}

\author{
Maud Schall'1, Patrick Lebene Adonoo², Seth Christopher Yaw Appiah ${ }^{3,4}$ (1) \\ ${ }^{1}$ Faculty of Creative Art and Technology, Kumasi Polytechnic, Kumasi, Ghana \\ ${ }^{2}$ School of Government, Sun Yat-sen University, Guangzhou, China \\ ${ }^{3}$ Department of Sociology and Social Work, Kwame Nkrumah University of Science and Technology, Kumasi, Ghana \\ ${ }^{4}$ Ludwig-Maxmilian Universitate, LMU-Centre for International Health-University of Munich, LMU, Munchen, Germany \\ Email: Schallmaud@yahoo.com,sychrist_2007@yahoo.com
}

How to cite this paper: Schall, M., Adonoo, P. L., \& Appiah, S. C. Y. (2019). Exploring the Utility of Word of Mouth Advertisement in Improving Product Sales: The Case of Selected Companies in the Kumasi Metropolis of Ghana. Advances in Applied Sociology, 9, 227-241.

https://doi.org/10.4236/aasoci.2019.96018

Received: April 10, 2019

Accepted: June 24, 2019

Published: June 27, 2019

Copyright $\odot 2019$ by author(s) and Scientific Research Publishing Inc. This work is licensed under the Creative Commons Attribution International License (CC BY 4.0).

http://creativecommons.org/licenses/by/4.0/

c) (i) Open Access

\begin{abstract}
Background: Advertisements constitute one of the principal tools organizations use in securing and retaining customers. This study assessed the effect of word of mouth advertising on product marketing in selected companies in the Ashanti region of Ghana. Data were obtained through a cross-sectional multistage sampling process. Methods: Ten (10) companies were purposely selected out of which 100 participants made up of both customers and staff of the companies was recruited at random and data collected through a simple closed ended questionnaire. Simple descriptive statistics were employed in characterizing the respondents and responses given. This was supported with standard multivariate regression analyses to detect the predictive powers of different mediums of word of mouth advertisement on sales margin and profitability. Results: In the cross-sectional analyses, telephone communication demonstrated significant direct effect on high sales margins $($ beta $=0.726, \mathrm{t}=$ $7.463, p<0.000$ ). Face to face communication is the most frequent word of mouth communication channel. Our model suggest that controlling for face to face communication, social networking, lectures, conference and seminars, telephones as a medium explains 72.6 percent of the variance in sales margin. Conclusion: Using the phone as a communication tool in advertising goods and services and for the companies has direct positive impact on the level of sales than other forms of word of mouth advertisement.
\end{abstract}

\section{Keywords}

Advertisement, Word of Mouth, Ghana, Marketing, Sales 


\section{Background}

Word of mouth advertisement is beginning to emerge as a great tool in the general marketing industry despite the limited research focus it has received in the past. The credibility of Word of Mouth marketing platform is not doubted (Huang et al., 2011) particularly when it is considered to go beyond friends and colleagues. Its utility in developing countries has been acknowledged by studies by Bughin and colleagues (Bughin, Doogan, \& Vetvik, 2010).

Companies over the world and Ghana particularly have for decades focused their advertising messages through print media leaving other equally, if not more effective media unused (East, 2007). Advertisement jingles have flooded local radio airwaves, TV commercials have for years been interrupting regular programming whilst large billboards inundate public streets all in a concerted effort towards taking advantage of the advertising avenues the radio, TV and print media have to offer.

With the use of these popular mediums reaching a saturation point in their influence on customers purchasing decisions (Casalo, Flavian, \& Guinaliu, 2008; Van Dolen, Dabholkar, \& Ruyter, 2007; Wang et al., 2007), it is imperative for other advertising platforms to be explored. The growing diversification of customers and widespread adoption of internet platforms by most of the youth require that integrated marketing communication strategies are adopted. However, the approach to adopt must be one that is effective in bringing the necessary returns. Advertisement has been found to effect some changes on consumer behaviour. As defined by Engel et al. (1993), consumer behaviour applies to those activities directly involved in obtaining, consuming and disposing of products and services, including the decision process that precedes and follow these actions. Engel et al. (1993) further identify a five stage process; the problem recognition stage, information search stage, evaluation of alternatives, purchase and post purchase evaluation.

According to Loudon \& Della, 1993; Wilkie, 1994; Solomon, 1993 and Brassington \& Petit (2006), customer decision can be categorized into extensive decision making, routine response behaviour and limited decision-making. In the quest to purchase, consumers first recognize a need for a product or a service and this is followed by a search of information for potential need satisfiers. In the view of Engel et al. (1993), information search constitute any action motivated by the knowledge and stored in memory or gaining information from the environment.

Information gathered may focus on gathering facts from colleagues or friends, comparison of brands and prices of available products, advertisement and other public sources (Dibb et al., 1997; Loudon \& Della Bitta, 1993; Ennew, 1993; Engel et al., 1993). A successful and good information search yields a group of brands for clients that he/she sees as possible alternatives. Dibb et al. (1997) call this group of brands or products the consumers evoked set. Consumers do not only conduct information search but also engage in evaluation of the informa- 
tion. The importance of evaluative criteria depends on the individual factor, the situational factor and the host of product (Engel et al., 1993; Loudon \& Della Bitta, 1993; Kotler et al., 1996).

Consumers seek assistance from the environment if they lack prior information about the choice of alternatives (Engel et al., 1993) after evaluation. Decision rules can also be differentiated into compensatory and non-compensatory (Solomon, 1993; Engel et al., 1993; Wilkie, 1994; Assael, 1984). Ennew (1993) and Assael (1984) share the opinion that the products that give the consumer the highest satisfaction amongst the other alternatives are purchased after the evaluation. Once the circumstance in the market remains unchanged or is stable, the decision made by the consumer to purchase the product will lead to actual purchase (Kotler et al., 1996; Ennew, 1993). However, the degree of instrumental action is more likely to vary for various degree of complexity of the decision making process (Assael, 1984).

The satisfaction or unsatisfactory level of the consumer will depend on the relationship between the expectation of the consumer and the product perceived performance (Kotler et al., 1996; Kotler, 1988) after its purchase. In the opinion of Dibg et al. (1997) the feelings experienced by the consumer will determine the complaint of the consumer, whether he/she will purchase the product again or say something good or bad about the product. Thus the driving force of external influence becomes paramount towards repeated purchase.

The influence exerted by an individual in the decision making process is critical in understanding consumer behaviour. The manner of the individual consumer influence can be categorized into personal and psychological factors (Kotler, 1988). The key influences on consumer behaviour are; the personality and self-concept of the consumer, motivation, perception, learning and the influence on attitudes (Kotler, 1997; Dibb et al., 1997; Brassington \& Pettitt, 2006; Kotler et al., 1996). What a consumer has learnt and stored in memory significantly affect any situation that they face (Engel et al., 1993; Wilkie, 1994). Thus selective retention is the act of remembering personal information input that support feelings and forgetting those that do not support feelings (Kotler, 1997; Dibb et al., 1997; Brassington \& Pettitt, 2006). It is at this level that word of mouth advertisement mediums demonstrates their utility in facilitating repeated purchase by consumer.

The appeal to the emotions and senses of consumers become very forceful in product selection. Santo (2003) defines Word of Mouth Advertisement (WOM) as the opinions, suggestions made by consumers of a particular product to their friends and close associates. Froehle (2006) extends further by explaining that word of mouth advertisement comes as positive testimonies about a product or service made orally by a trusted individual. A trusted individual in this sense could represent a friend, family member or acquaintance. Accordingly Godes \& Mayzlin (2004), emphasis on friends, family and acquaintances in defining WOM advertisement is misplaced and limits the scope of word of mouth advertisement and that word of mouth extends beyond face-to-face or direct commu- 
nication but also encompasses other forms of indirect communication forms like electronic and online media. This makes the scope of word of mouth communication inclusive of both direct and indirect communication forms.

The electronic word of mouth advertisement according to Nguyen et al. (2014) takes place where when former or potential customer discusses the offerings of a company in positive or negative light to either one person or expose it to a multitude of people by electronic means. With regard to online word of mouth advertising, customer ratings (Gauri et al., 2008 and Chevalier \& Mayzllin, 2006) and interactions through social media are critical components. Word of mouth advertisement platforms are mostly culturally immersed and appear not too distant from the consumer. They are considered in the realist domain and appear much more trusting.

According to Assael et al. (1984), culture is the customs, norms and values learnt by individual from the society that results in a common behaviour pattern within the society. In a situation where the product or service moves in accordance with values, norms and customs of the society there is a chance of the good or service being accepted at the market place (Solomon, 1993). When culture is not on the broader spectrum, the values, norms and attitudes of people are similar (Dibb et al., 1997; O'Shaughnesy, 1995). The social class of an individual gives a distinct preference of a good or service that he/she may purchase (Kottler, 1997; Ennew, 1993). Income, occupation, lifestyle, education and values or prestige are measures for social class (O'Shaughnesy, 1995) which influence consumers in purchasing products. Brand decision is likely to influence the decision of a reference group if the product is more conspicuous (Dibb et al., 1997; Kotler, 1988). A reference group can also serve as a source of information for an individual to determine the type of products to buy and where to buy such products. The family also largely affect the purchasing decision of that individual consumers (Brassington \& Pettitt, 2006). Family recommendation and reference group endorsement account largely as word of mouth advertisement platforms.

The question of word of mouth advertisement mediums comparative cost benefit advantage over other advertisement mediums remains a continuing inconclusive research domain. Notwithstanding, some studies have reported positive effect with relatively higher comparative advantage of word of mouth advertisements on sales margin than other marketing communicating tools. In the study of Monahan (1984) and Hogan et al. (2004), word of mouth advertisement generated a ripple effect on sales margin making the effect of word of mouth advertising a long-term one.

There is also an increase in organizational work performance as a result of word of mouth advertisement (Luo, 2009; Trusov et al., 2009). Analysis has revealed that the role of advertising in WOM is stronger such that many consumers ascribe high credibility to the information they hear from WOM conversation; which highly influence them in their purchasing decisions (Keller \& Fay, 2012). According to Villanueva, Yoo, \& Hanssens (2008) customers who ac- 
quired product information by means of WOM add more long-term value to an organization than customers who obtained by means of traditional channels of marketing.

Similarly, in other studies WOM was found to be two times more effective than radio advertisements, four times more than personal selling and seven times more than print advertisements (Katz \& Lazarsfeld, 1966). Chevalier \& Mayzlin (2006) reported an improvement in a book's reviews which resulted in increase in relative sales. In that study, Amazon.com and Barnesandnoble.com online stores as were employed as a proxy for WOM advertisement and its influence on sales. Liu (2006) shares stated that WOM increase performance (box office revenue).

Accordingly, online WOM has been found to contribute to higher relative sales (Chevalier \& Mayzlin, 2006; Liu, 2006). Bughin, Doogan, \& Vetvik (2010) reiterate how WOM powerfully influences marketing which caused McKinsey \& Co. to label it "the most disruptive force in marketing".

The study of Adiko (2015) in Ghana exploring the application of integrated marketing communication strategies on brand performance of three private universities demonstrates key findings that confirm the potency of word of mouth advertisement over other marketing tools. In the study, it was reported that while $40 \%$ (60) of the students got to know about their schools through referrals or mouth of mouth advertisement, those bill boards and internet sources informed $30 \%$ and $20 \%$ of the students with radio not contributing to any of the student who enrolled. This finding was despite the huge investment made by the schools in radio advertisement as confirmed by the marketing managers of the three universities. Despite the reported positive effect word of mouth makes on sales margin, service uptake and by extension profit, little is known within the Ghanaian landscape on its efficacy in non-formal businesses and in other related business environments.

The use of word of mouth advertisement has been underutilized by organisations in Ghana who have had to spend appreciable amounts on advertisement. There is little scholarly works that have delved into this area as an advertisement model in the Ghanaian marketing landscape, necessitating the conduct of this study. This study assesses the effects of word of mouth advertisement on product sales margin focusing on selected companies operating in the Ashanti region of Ghana.

\section{Methods}

\subsection{Study Design and Setting}

Quantitative cross sectional design was used in the study to present an accurate characteristics of the sampled respondents and data samples/categories. The cross sectional study design is used to collect information from a section of the population within a short time (Levin, 2006). The study was conducted within the Kumasi metropolis. The Kumasi metropolis is host to the Ashanti regional 
capital-Kumasi with numerous business establishments. The selected companies are all located and distributed across the various sub-metros within the Kumasi metropolis. The selected companies included Avros Limited, Sambra Hotel and Restaurant Limited, Blue Crest Institute, Halleluyah Ventures, Abaanekie Enterprise, City Style Hotel, Cityville Investments, MultiCredit Savings and Loans, Angel FM and Adutwumwaa Herbal Industries. These are private owned establishments located at within the Kumasi Metropolis. These companies were selected because they have a tradition for engaging in large scale advertisement due to the nature of their products. The companies reflect the tourism sector, banking and financial sector, pharmaceutical industry, radio and industry, retailing industry and the wholesale sector.

\subsection{Population and Sampling}

The study recruited 100 study participants involving customers and staff of the 10 purposively selected companies. The sampled companies were selected purposively to represent varieties of market segments and businesses. The 30 staff involved key management members of the companies who were directly linked with marketing of the products. Three employees were sampled from each of the 10 companies. In some companies, senior managers of the companies were sampled. In respect to the staff, participants were conveniently sampled while ensuring that various units within each establishment had a representation to cater for the variation in different units in the company.

In all 7 customers from each company was sampled. The customers sampled at the exit/entry points were customers who purchased the services from the target institutions and also sold the products/services to other clients. The sampling of the customers was facilitated through unit/facility exit approach. In this way, customers who had purchased products or accessed services from any of the selected companies and were about exiting the premises were enrolled. This approach was adopted so that the determining factor that lead to their purchase of the company's product or service could be easily elicited.

\subsection{Data Collection}

The self-administered questionnaire adopted was concise and close-ended, to allow for quick guided responses so as to enable categorization. A 5-point Likert scale was used in measuring responses obtained. The question items were pre-tested on 5 randomly selected staff of Multi Credit Savings and Loans Limited. The same questionnaire was administered to both staff and customers eliciting respondents perspective on word of mouth advertisement platforms and effect of word of mouth on sale/purchase.

\subsection{Data Analysis}

After the data was collected, it was coded into the Statistical Package for Social Sciences (SPSS) computer software. The data was analyzed through descriptive 
and inferential statistics using frequency tables and regression analysis. Multivariate analyses was conducted to examine the predictive powers of different forms of word of mouth advertisement utilized by participants on sales margin.

\subsection{Ethical Requirements}

Ethical standards were strongly adhered to in the conduct of the study. Study participants were briefed on the importance of this study and their personal details were not also taken. Assurance of strict privacy in terms of possibly not revealing their company profit related information was ensured. Informed consent, confidentiality and data protection were adhered to. Both verbal and written informed consent was sought.

\section{Results}

\subsection{Background Characteristics of Study Participants}

The demographic characteristics of the participants included age, gender, marital status and academic qualification. The majority $47 \%$ of the study participants were aged 46 - 60 years, 38\% aged between 36 - 45 years and 18\% between 26 35 years. Males $76 \%$ dominated in the sampled industries. There were $73 \%$ of the population who were married with nearly 8 out of every ten participant $(77 \%)$ having attained education up to the tertiary level. $16 \%$ of the workers and senior management members had attained postgraduate level training with less than ten percent (7\%) having secondary education. See Table 1.

Table 1. Demographic characteristics of respondents.

\begin{tabular}{|c|c|c|}
\hline Variable & $\mathbf{N}$ & $\%$ \\
\hline \multicolumn{3}{|l|}{ Age } \\
\hline$-18-25$ & 02 & 02 \\
\hline$-26-35$ & 13 & 13 \\
\hline$-36-45$ & 38 & 38 \\
\hline$-45-60$ & 47 & 47 \\
\hline \multicolumn{3}{|l|}{ Gender } \\
\hline - Male & 76 & 76 \\
\hline - Female & 24 & 24 \\
\hline \multicolumn{3}{|l|}{ - Marital Status } \\
\hline - Married & 73 & 73 \\
\hline - Single/Divorced & 27 & 27 \\
\hline \multicolumn{3}{|l|}{ Academic Qualification } \\
\hline - Low/Basic & - & - \\
\hline - Intermediate/Secondary & 07 & 07 \\
\hline - High/Tertiary & 77 & 77 \\
\hline - Very High/Postgraduate & 16 & 16 \\
\hline
\end{tabular}




\subsection{Effectiveness of Word-of-Mouth as a Marketing Tool}

The study assessed how effective word of mouth was as a marketing tool. Both employees and employers perspectives were elicited and presented in Figure 1. The study found $90.0 \%$ of customers and $93.0 \%$ of staff affirming word of mouth as an effective marketing tool. The large percentage pool of respondents thus agrees that word of mouth constitute an effective marketing tool.

\subsection{Effect of Different Word-of-Mouth Mediums on Sales Margins}

Linear simple regression analysis was conducted to assess the effectiveness of each Word-of-Mouth channel on sales margins. In this analysis, sales margin was treated as the study dependent variable, whiles channels of word of mouth advertising (Face to Face communication, social networking, telephones, lectures, seminars and conferences) were treated as independent variables. Study participants were evaluated on their value judgement of how each medium of word of mouth advertisement contributed to sales margin improvement against their own set target benchmarks by virtue of their own direct use of word of mouth advertisement medium in the past.

The model;

$\mathbf{Y}=\mathbf{a}+\mathbf{b}_{1} \mathbf{x}_{1}$, generally predicts telephone communication to be more effective than the other variables. From the model, $\mathrm{Y}$ is the dependent variable; $\mathrm{a}$, is a constant; $b_{1}$ is the coefficient of the independent variable $x_{1}$ (High sales margins). It can be inferred that telephone communication has significant direct effect on high sales margins (beta $=0.726, t=7.463, p<0.000$ ). An increase in the face to face word of mouth advertisement with clients by either a staff or a customer about the product of the company has the potential to improve or bring about increase in sales margin by 0.74 percent holding all other factors constant (Table 2).

\subsection{Customer Level of Usage of Different Mediums of Word-of-Mouth Advertisement}

Table 3 shows the level of usage of the various channels of word of mouth advertising as determined by customers of the selected companies. In analyzing these responses, the study conducted a statistical mean analysis to determine the central location (average) of the data to help the study analyze the significance of the gaps between the various mean figures. A smaller mean value corresponds to a higher level of usage of a particular channel of word of mouth advertising. The mean values showed that face-to-face communication $($ mean $=0.2286)$, social networking (mean $=0.3000)$ and telephone communication $($ mean $=0.5143)$ are utilized far often by a greater number of people than lectures (mean $=0.8429$ ), conferences $($ mean $=0.8000)$ and seminars $($ mean $=0.8429)$. The study therefore shows that face-to-face communication, social networking and telephones are used much more frequently than the other channels (lectures, conferences and seminars. 


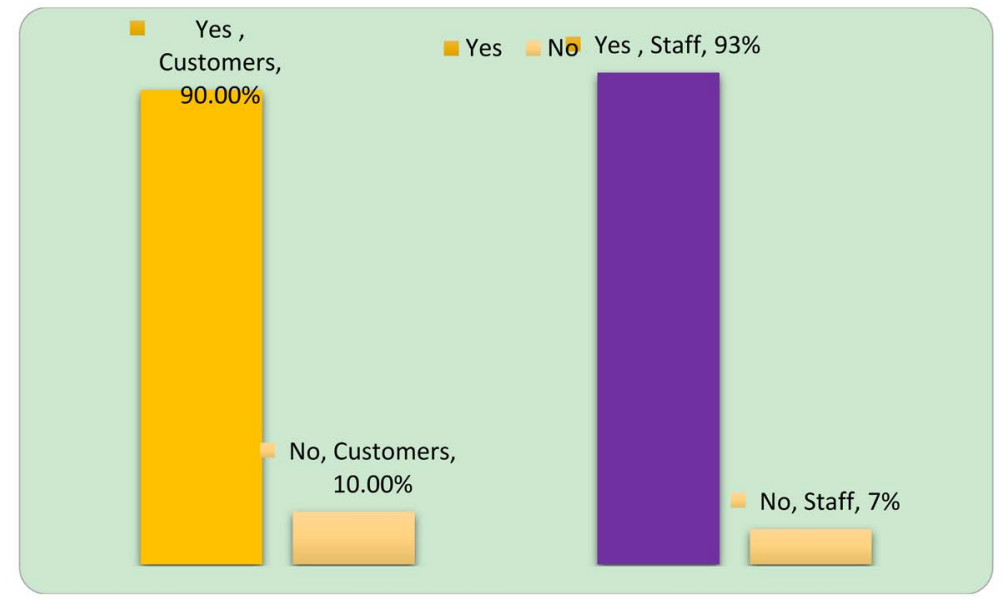

Figure 1. Effectiveness of word-of-mouth as a marketing tool.

Table 2. Linear regression on effect of different word of mouth advertisement medium on sales margin.

\begin{tabular}{|c|c|c|c|c|c|c|}
\hline & \multirow[t]{2}{*}{ Model } & \multicolumn{2}{|c|}{$\begin{array}{l}\text { Unstandardized } \\
\text { Coefficients }\end{array}$} & \multirow{2}{*}{$\begin{array}{c}\begin{array}{c}\text { Standardized } \\
\text { Coefficients }\end{array} \\
\text { Beta }\end{array}$} & \multirow[t]{2}{*}{$\mathrm{t}$} & \multirow[t]{2}{*}{ Sig. } \\
\hline & & B & Std. Error & & & \\
\hline \multirow{7}{*}{1} & (Constant) & -0.034 & 0.064 & & -0.530 & 0.597 \\
\hline & $\begin{array}{c}\text { Face to Face } \\
\text { Communication }\end{array}$ & 0.151 & 0.091 & 0.135 & 1.663 & 0.100 \\
\hline & Social Networking & 0.011 & 0.074 & 0.011 & 0.143 & 0.887 \\
\hline & Telephones & 0.743 & 0.100 & 0.726 & 7.463 & 0.000 \\
\hline & Lectures & 0.050 & 0.081 & 0.051 & 0.614 & 0.541 \\
\hline & Conferences & 0.079 & 0.085 & 0.087 & 0.929 & 0.355 \\
\hline & Seminars & 0.008 & 0.072 & 0.007 & 0.109 & 0.913 \\
\hline
\end{tabular}

Dependent Variable: Sales margins.

Table 3 Customer level of usage of various word-of-mouth Advertising channels $(\mathrm{N}=$ 70).

\begin{tabular}{ccc}
\hline Medium & Mean & Std. Deviation \\
\hline Face to face communication & 0.2286 & 0.42294 \\
Social networks & 0.3000 & 0.46157 \\
Telephones & 0.5143 & 0.50340 \\
Lecture & 0.8429 & 0.36656 \\
Conferences & 0.8000 & 0.40289 \\
Seminar & 0.8429 & 0.36656 \\
\hline
\end{tabular}

\subsection{Staff Level of Usage Level of the Various Word-of-Mouth Advertising Channels'}

Table 4 presents staff responses regarding the level of usage of word of mouth 
advertising channels. Analysis of the mean values shows that face to face communication (0.300) is the preferred word of mouth communication channel followed by seminar (0.5000) and telephone (0.533). The coefficient of variation for face to face communication was higher (15.54) among all the mediums used and preferred by staff. A large coefficient of variation indicates that the data has a great deal of variability with respect to the mean whiles a small coefficient of variation shows a general consensus among the sample respondents.

\subsection{Correlation Test of Word of Mouth Advertising Channels}

The relationship between the various channels of word of mouth advertising as determined by both staff and customers was explored using a correlation matrix analysis. The variables used in this test were the channels of word of mouth advertising which included, face-to-face advertising, social networks, telephone marketing, lectures, conferences and seminars. The correlation test showed that the various channels of word of mouth advertising, face-to-face advertising, social networks, telephone marketing, lectures, conferences and seminars were all significantly correlated, one to another. The mediums that are strongly correlated are were conference and seminar $(r=0.788)$, lectures and conference $(r=$ $0.777)$, lectures and seminar $(r=7.36)$, social network and face to face communication $(r=0.626)$. Others were social network medium and telephone $(r=$ $0.525)$, telephone and conference $(r=0.585)$ and telephone and seminar $(r=$ $0.571)$. The results are presented in Table 5.

\section{Discussion}

The present cross sectional quantitative study explores the relationship that exist between word of mouth advertisement platforms and sale margin. The study shows that the drive towards entrepreneurship grows stronger as people age and is almost entirely non-existent before the age of 25 years. With the majority of the participant within the age cohort of $45-60$ years (47\%), it is instructive that the participants working within these private establishments have had life time exposures and might have encountered different product sales approaches either one time as customers who patronize services or as staff who define sales approaches.

This finding is an indication of the level of entrepreneurship amongst the various age levels in the Ghanaian society grows with age. In the study, sales margin was treated as the study dependent variable, whiles channels of word of mouth advertising (Face to Face Communication, Social Networking, Telephones, Lectures, Seminars and Conferences) were treated as independent variables The study identified that among both staff and customers 9 out 10 affirmed the effectiveness of word of mouth advertisement as an effective tools for sales improvement. Consistent with Marsden (2005) in his studies concluded that the use of word of mouth is $50 \%$ more used and preferred as sales tool now than the past three decade. 
Table 4. Level of usage level of the various word-of-mouth advertising channels by staff $(\mathrm{N}=30)$.

\begin{tabular}{cccc}
\hline & Mean & Std. Deviation & CV \\
\hline Face to face communication & 0.3000 & 0.46609 & 15.54 \\
social networks & 0.8333 & 0.37905 & 4.55 \\
Telephones & 0.5333 & 0.50742 & 9.51 \\
Lecture & 0.8333 & 0.37905 & 4.55 \\
Conferences & 0.6667 & 0.47946 & 7.19 \\
Seminar & 0.5000 & 0.50855 & 10.17 \\
\hline
\end{tabular}

Table 5. Correlation test of word of mouth advertising channels.

\begin{tabular}{|c|c|c|c|c|c|c|c|}
\hline Meduim & & Face to & $\mathrm{SN}$ & Tele & Lect & Conf & Semins \\
\hline \multirow{2}{*}{ Face to Face $(\mathrm{F})$} & Pearson Corr & 1 & $0.626^{* *}$ & $0.370^{* *}$ & $0.252^{*}$ & $0.270^{* *}$ & 0.079 \\
\hline & Sig. (2-tailed) & & 0.000 & 0.000 & 0.011 & 0.007 & 0.435 \\
\hline \multirow{2}{*}{ Social Networking } & Pearson Corr. & $0.626^{* *}$ & 1 & $0.525^{* *}$ & $0.239^{*}$ & $0.284^{* *}$ & 0.090 \\
\hline & Sig. (2-tailed) & 0.000 & & 0.000 & 0.017 & 0.004 & 0.375 \\
\hline \multirow{2}{*}{$\begin{array}{c}\text { Telephone } \\
\text { Communication }\end{array}$} & Pearson Correl & $0.370^{* *}$ & $0.525^{* *}$ & 1 & $0.454^{* *}$ & $0.585^{* *}$ & $0.571^{* *}$ \\
\hline & Sig. (2-tailed) & 0.000 & 0.000 & & 0.000 & 0.000 & 0.000 \\
\hline \multirow{2}{*}{ Lectures } & Pearson Corr & $0.252^{*}$ & $0.239^{*}$ & $0.454^{* *}$ & 1 & $0.777^{* *}$ & $0.736^{* *}$ \\
\hline & Sig. (2-tailed) & 0.011 & 0.017 & 0.000 & & 0.000 & 0.000 \\
\hline \multirow{2}{*}{ Conferences } & Pearson Correl & $0.270^{* *}$ & $0.284^{* *}$ & $0.585^{* *}$ & $0.777^{* *}$ & 1 & $0.788^{* *}$ \\
\hline & Sig. (2-tailed) & 0.007 & 0.004 & 0.000 & 0.000 & & 0.000 \\
\hline \multirow{2}{*}{ Seminars } & $\begin{array}{l}\text { Pearson } \\
\text { Correlation }\end{array}$ & 0.079 & 0.090 & $0.571^{* *}$ & $0.736^{* *}$ & $0.788^{* *}$ & 1 \\
\hline & Sig. (2-tailed) & 0.435 & 0.375 & 0.000 & 0.000 & 0.000 & \\
\hline
\end{tabular}

${ }^{*}$ Correlation is significant at the 0.01 level (2-tailed). ${ }^{\star}$ Correlation is significant at the 0.05 level (2-tailed).

This explains why modernized forms of word of mouth advertisement such as internet and mobile phones have spiraled the advertisement industry outpacing traditional marketing communication. On the customer front, the study found face-to-face word of mouth communication medium (mean $=0.2286$ ), social networking (mean $=0.3000)$ and telephone communication $($ mean $=0.5143)$ as the frequently used word of mouth advertisement. Whiles face to face word of mouth communication medium is the dominant word of mouth advertisement medium used by staff, it is rather often complemented with seminars $(0.5000)$ and telephone (0.533) unlike customers who complemented word of mouth with social networking.

A common observation stands out, the acknowledgement and use of word of mouth and telephone as the predominant means of word of mouth advertisement mediums by both customer and staff of the companies. In the correlation analysis, face to face and telephone was found to be significantly correlated $(\mathrm{r}=$ 
0.370) as confirmed by both customers and management of the companies but this correlation did not appear extremely strong compared to other combined mediums.

A combined perspective eliciting the correlation of different word of mouth approaches demonstrates the need for both customers and company management to complement their word of mouth activities with its evidenced based strongly correlated channels. Thus, the strongest correlated mediums were found to be conference and seminar $(r=0.788)$. This finding does not appear to be what customers and company managers themselves use as the best combined mediums were face to face followed by social networking for customers and face to face followed by seminars by staff.

Though many companies are known to sponsor seminars and participate in some, it is little wonder that the evidence from this study identify seminars as a second to face to face word of mouth advertising channel over other channels such as social networking and lectures. It is fair to say that the social networking phenomenon that has hit Ghanaian landscape is yet to be fully used as principal advertisement medium by most Ghanaian companies. It is possible to understand the target market audience of the selected companies before appreciating their moderate use of social media and other combine word of mouth advertisement mediums. This comes at the back of credibility issues that may come along with staff advertising their products via word of mouth on social networking platforms. Online fraud, company representative theft and identify crime might be among the many factors that rise to water down Tancer (2008) submissions on the utility of social media. Both Tancer (2008) and Lazardsfeld are right when they assert that social networking represents one of the surest and cheapest mechanisms for business thrive and an effective public relations for providing key information to customers and enabling customers to share experiences and options.

Social network advantage of a larger geographical and demographical scope compared to other advertising media such as radio, television and print have been itemized though customers and management of companies are being cautious in a full scale adoption and use

The study showed that telephone communication has significant direct effect on high sales margins. This implies using the phone as a communication tool in advertising goods and services and for companies it has direct positive impact on the level of sales that company receives in the period of the telephone advertisement.

This finding is consistent with studies by Katz \& Lazarsfeld (1966) who found that the most important factor that influence consumer's purchases of food product and household goods was WOM advertisement. In their studies it was found that WOM is twice highly effective as advertising on the radio, four times as effective as selling personally to consumers and seven times also effective as magazines and newspapers. Similar confirmation on the effect of word of mouth advertisement on increasing sales margin has been noted by Engel et al. (1969). 
It has been found in Engel et al. study that on the adoption of automotive diagnostic centre that $60 \%$ of consumers confirmed word of mouth advertisement as the most influential factor in accepting such a service. Herr et al. (1991) indicated that WOM communication is much stronger than information from other neutral sources like a magazine.

Other variables of word of mouth advertising were found not to have any significant effects on the sales margins of the company. This could mean that though the use of the other variables improves marketing and company image that does not directly translate into tangible sales figures. Thus, the study shows that it is only telephone communication in the advertising process that ensured significantly higher sales for companies and that though the other mediums may bring some sales, the sales margins may not be significant. Word of mouth advertisement are more likely to be trusted by consumers and prospective buyers (Burmaster, 2008)

\section{Limitation}

The study is limited by its inability to use the financial performance data of the selected companies to link it up with which client patronized their services or product. This matching would have been the best way of exploring the relationship between advertisement platforms and sales margin. However, the present cross sectional design is equally adequate as the sampling strategy made great efforts in enrolling study participants who were directly in the known of word of mouth platforms and their business sales portfolios. Their account was deemed strong enough to guarantee the study findings reliable and valid. In such instances, the findings are not only perception but reflect reported observation from business practitioner's point of view.

\section{Conclusion}

Word of mouth advertisement offer prospects for increasing sales margin of companies. The attempts to make giant costly advertisement may come with its own target customs and audience but calls for a cost benefit analysis. While the coverage of word of mouth may be limited compared to other advertisement mediums and options, it remains potent when the different mediums are combined, strategically employed and the sales and profitability returns assessed.

\section{Author Contributions}

MS and SCYA conceived and designed the study wrote the first draft of the manuscript, analysed the data and PLA proofread the draft of the manuscript. All authors agreed to the publication.

\section{Funding}

The study was self-funded by the authors. 


\section{Acknowledgements}

We are grateful to the workers who availed themselves for the interviews.

\section{Conflicts of Interest}

The authors declare no conflicts of interest regarding the publication of this paper.

\section{References}

Adiko, E. A. (2015). Integrated Marketing Communications Strategies on Brand Performance: A Study on three Private Institutions in Ghana. Journal of Applied Thought, 4.

Assael, H. (1984). Consumer Behavior and Marketing Action. Kent Pub. Co.

Brassington, F., \& Pettitt, S. (2006). Principles of Marketing. London: Pearson Education.

Bughin, J., Doogan, J., \& Vetvik, O. J. (2010). A New Way to Measure Word-of-Mouth Marketing. McKinsey Quarterly, 2, 113-116.

Casalo, L. V., Flavián, C., \& Guinalíu, M. (2008). The Role of Satisfaction and Website Usability in Developing Customer Loyalty and Positive Word-of-Mouth in the e-Banking Services. International Journal of Bank Marketing, 26, 399-417. https://doi.org/10.1108/02652320810902433

Chevalier, J. A., \& Mayzlin, D. (2006). The Effect of Word of Mouth on Sales: Online Book Reviews. Journal of Marketing Research, 43, 345-354. https://doi.org/10.1509/jmkr.43.3.345

Dibb, S., Simkin, L., Pride, W. M., \& Ferrell, O. C. (1997). Marketing: Concepts and Strategies (3rd European ed.). Boston, MA: Houghton Mifflin.

East, R., Hammond, K., \& Wright, M. (2007). The Relative Incidence of Positive and Negative Word of Mouth: A Multi-Category Study. International Journal of Research in Marketing, 24, 175-184. https://doi.org/10.1016/j.ijresmar.2006.12.004

Engel, J. F., Blackwell, R. D., \& Miniard, P. W. (1993). Consumer Behavior. New York: Dreyden Press.

Engel, J. F., Kegerreis, R. J., \& Blackwell, R. D. (1969). Word-of-Mouth Communication by the Innovator. The Journal of Marketing, 33, 15-19.

https://doi.org/10.1177/002224296903300303

Ennew, C. T. (1993). The Marketing Blueprint. Oxford: Blackwell.

Froehle, C. M. (2006). Service Personnel, Technology, and Their Interaction in Influencing Customer Satisfaction. Decision Sciences, 37, 5-38. https://doi.org/10.1111/j.1540-5414.2006.00108.x

Gauri, D. K., Bhatnagar, A., \& Rao, R. (2008). Role of Word of Mouth in Online Store Loyalty. Communications of the ACM, 51, 89-91. https://doi.org/10.1145/1325555.1325572

Godes, D., \& Mayzlin, D. (2004). Using Online Conversations to Study Word-of-Mouth Communication. Marketing Science, 23, 545-560. https://doi.org/10.1287/mksc.1040.0071

Herr, P. M., Kardes, F. R., \& Kim, J. (1991). Effects of Word-of-Mouth and Product-Attribute Information on Persuasion: An Accessibility-Diagnosticity Perspective. Journal of Consumer Research, 17, 454-462. https://doi.org/10.1086/208570

Hogan, J. E., Lemon, K. N., \& Libai, B. (2004). Quantifying the Ripple: Word-of-Mouth and Advertising Effectiveness. Journal of Advertising Research, 44, 271-280. 


\section{https://doi.org/10.1017/S0021849904040243}

Huang, M., Cai, F., Tsang, A. S. L., \& Zhou, N. (2011). Making Your Online Voice Loud: The Critical Role of WOM Information. European Journal of Marketing, 45, 1277-1297. https://doi.org/10.1108/03090561111137714

Katz, E., \& Lazarsfeld, P. F. (1966). Personal Influence, the Part Played by People in the Flow of Mass Communications. Piscataway, NJ: Transaction Publishers.

Keller, E., \& Fay, B. (2012). The Face-to-Face Book: Why Real Relationships Rule in a Digital Marketplace. New York: Simon and Schuster.

Kotler, P. (1988). Marketing Management: Analysis, Planning, Implementation, and Control. Englewood Cliffs, NJ: Prentice-Hall.

Kotler, P., Armstrong, G., Saunders, J., \& Wong, V. (1996). Principles of Marketing (European Edition). Hertfordshire: Hemel Hempstead.

Levin, K. A. (2006). Study Design III: Cross-Sectional Studies. Evidence-Based Dentistry, 7, 24-25. https://doi.org/10.1038/sj.ebd.6400375

Liu, Y. (2006). Word of Mouth for Movies: Its Dynamics and Impact on Box Office Revenue. Journal of Marketing, 70, 74-89. https://doi.org/10.1509/jmkg.70.3.74

Loudon, D. L., \& Della Bitta, A. J. (1993). Consumer Behaviour: Concepts and Applications (4th ed.). New York: McGraw-Hill.

Luo, X. (2009). Quantifying the Long-Term Impact of Negative Word of Mouth on Cashews and Stock Prices. Marketing Science, 28, 148-166.

https://doi.org/10.1287/mksc.1080.0389

Monahan, G. (1984). A Pure Birth Model of Optimal Advertising with Word-of-Mouth. Marketing Science, 3, 169-178. https://doi.org/10.1287/mksc.3.2.169

Nguyen, H., Groth, M., Walsh, W., \& Hennig-Thurau, T. (2014). The Impact of Service Scripts on Customer Citizenship Behavior and the Moderating Role of Employee Customer Orientation. Psychology \& Marketing, 31, 1096-1109.

https://doi.org/10.1002/mar.20756

O’Shaughnessy, J. (1995). Competitive Marketing (3rd ed.). London, New York: Routledge.

Santos, J. (2003). E-Service Quality: A Model of Virtual Service Quality Dimensions. Managing Service Quality: An International Journal, 13, 233-246.

https://doi.org/10.1108/09604520310476490

Solomon, M. R. (1993). Consumer Behavior. London: Allyn \& Bacon.

Trusov, M., Bucklin, R., \& Pauwels, K. (2009). Effects of Word of Mouth versus Traditional Marketing: Findings from an Internet Social Networking Site. Journal of Marketing, 73, 90-102. https://doi.org/10.1509/jmkg.73.5.90

Van Dolen, W. M., Dabholkar, P. A., \& De Ruyter, K. (2007). Satisfaction with Online Commercial Group Chat: The Influence of Perceived Technology Attributes, Chat Group Characteristics, and Advisor Communication Style. Journal of Retailing, 83, 339-358. https://doi.org/10.1016/j.jretai.2007.03.004

Villanueva, J., Yoo, S., \& Hanssens, D. M. (2008). The Impact of Marketing-Induced versus Word-of-Mouth Customer Acquisition on Customer Equity Growth. Journal of Marketing Research, 45, 48-59. https://doi.org/10.1509/jmkr.45.1.48

Wang, K. C., Hsieh, A. T., Chou, S. H., \& Lin, Y. S. (2007). GPTCCC: An Instrument for Measuring Group Package Tour Service. Tourism Management, 28, 361-376. https://doi.org/10.1016/j.tourman.2006.04.017

Wilkie, W. L. (1994). Consumer Behaviour. Hoboken, NJ: Willey Publishers. 